\title{
Meningkatkan Hasil Belajar Siswa pada Mata Pelajaran Matematika Materi Lingkaran Melalui Metode Cooperative LearningTipe Jigsaw II Di Kelas VIII A MTs Negeri 9 Ngawi Tahun Pelajaran 2017/2018
}

\author{
Suyani \\ MTs Negeri 9 Ngawi
}

\begin{abstract}
Abstrak
Penelitian ini bertujuan untuk mengetahui dan mendeskripsikan peningkatan hasil belajar siswa pada mata pelajaran matematika materi lingkaran metode cooperative learning tipe jigsaw di kelas VIII-A MTs N 9 Ngawi tahun pelajaran 2017/2018.Peneitian ini merupakan penelitian tindakan kelas (action research) karena dilakukan untuk memecahkan masalah pemeblajaran di kelas. Penelitian ini merupakan penelitian deskriptif karena menjabarkan bagaimana suatu teknik pembelajaran diterapkan dan bagaimana hasil yang diinginkan dapat dicapai. Subjek penelitian adalah siswa kelas VIIIA MTsN 9 Ngawi. Prosedur penelitian dengan melakukan tahap persiapan, pelaksanaan, dan penyelesaian.Hasil penelitian menunjukkan bahwa model pembelajaran cooperative learning tipe Jigsaw II memiliki dampak positif dalam meningkatkan hasil belajar siswa pada mata pelajaran matematika di kelas VIII A MTsN 9 Ngawi. Hal ini dapat dilihat dari perbandingan siklus I dan siklus II yaitu terjadi peningkatan. Rata-rata nilai siswa pada siklus I yaitu 69.22 kemudian pada siklus II menjadi 87.96. Rata-rata nilai kelompok pada siklus I yaitu 58.27 kemudian rata-rata nilai kelompok siklus II menjadi 93.85. Rata-rata skor akhir 1 ke siklus II meningkat 21\% Jumlah siswa yang mencapai KKM pada siklus I yaitu 3\% kemudian pada siklus II berkumlah $100 \%$. Hal tersebut sudah sesuai dengan target keberhasilan yang dicapai yaitu KKM $\geq$ $80 \%$.
\end{abstract}

Kata kunci :Hasil belajar, Lingkaran,Cooperative learning, Jigsaw.

\section{PENDAHULUAN}

Pendidikan merupakan suatu sarana untuk meninkatkan harkat dan marbatat bangsa. Pembangunan dalam bidang pendidikan harus melibatkan berbagai pihak secara berkerja sama untuk mewujudkan masyarakat Indonesia yang berkualitas, cerdas, mandiri dan berbudi luhur. UndangUndang No. 20 Tahun 2003 tentang Sistem pendidikan Nasional mendefinisikan Pendidikan sebagai Usaha sadar dan terencana untuk mewujudkan suasana belajar dan proses pembelajaran agar peserta didik secara aktif mengembangkan potensi dirinya untuk memiliki muatan spiritual keagamaan, penendalian diri, kepribadian, kecerdasan, akhlak mulia, serta keterampilan yang diperlukan dirinya, masyarakat, bangsa dan negara (Depdiknas, 2003). Denganmemperhatikan definisi di atas tampak secara jelas bahwa pendidikan di Indonesia tidak hanya dalam bidang ilmu pengetahuan, tetapi juga dalam bidang keterampilan.

Peran pendidikan sangat berperan dalam mempersiapkan sumber daya manusia yang unggul. Model pembelajaran, strategi pembelajaran, serta metode pembelajaran yang dipakai dalam kegiatan pembelajaran termasuk faktor-faktor yang menentukan tingkat keberhasilan peserta $\operatorname{didik(Uno,~}$ 2010). Faktor penentu keberhasilan peserta didik dalam belajar dikategorikan menjadi dua yaitu faktor internal dan ekstenal. Faktor internal berkaitan dengan diri peserta didik 
sedangkan faktor eksternal bersumber dari lingkungan belajar, sarana prasarana, orang tua, guru, teman sebaya dan masyarakat luas.

Harus diakui bahwa guru memainkan peranan utama dalam prosesmenghasilkan pendidikan yang berkualitas, dalam hal ini guru bukan satu-satunyasumber ilmu pengetahuan. Perlu dipikirkan dalam memajukan proses belajar mengajar adalah kurikulum, program-program pendidikan, sumber daya, fasilitas pendidikan, keuangan, manajemen dan kepemimpinanpendidikan. Karena berbagai alasan, pendidikan di sekolah-sekolah saat inimasih merupakan pendidikan yang berfokus pada pengajar (Teacher Centered)(Hara, 2009).

Konsentrasi utama dalam proses belajar mengajar terkonsentrasi pada aspek mengajar saja. Sehingga mengakibatkan pembelajaran matematika di MTsN 9 Ngawi belum mendapatkan hasil maksimal. Ada beberapa hal yang terjadi diantarannya motivasi belajar terhadap pelajaran matematika masih rendah, sulitnya mengajak siswa untuk aktif saat proses pembelajaran berlangsung, sehingga nilai matematika kelas VIII-A secara keseluruhan di bawah KKM. Menanggapi hal tersebut tentunya perlu dilakukan tindakan-tindakan yang dapat mengatasi masalah tersebut.

(Permana, 2016) Menyatakan bahwa metode pembelajaran kooperatif atau Cooperative Learning, sebagai suatu rangkaian kegiatan belajar di kelas, menekankan kepada konsep berpikir kritis, bersama dan bekerjasama dalam suatu kelompok kecil (3-5 orang siswa yang heterogen), dengan demikian hasil belajar siswa dapat meningkat.Maka dari itu, penelitian tindakan kelas ini mecoba menerapkan metode pembelajaran kooperatif tipe Jigsaw II.

Berdasarkan uraian diatas, maka peneliti ingin melakukan penelitian tindakan kelas dengan judul " Meningkatkan Hasil Belajar Siswa pada Mata Pelajaran Matematika Materi Sudut Pada Lingkaran Melalui Metode Cooperative Learning Tipe Jigsaw II di Kelas VIII-A MTsN 9 Ngawi "

\section{METODE PENELITIAN}

Penelitian ini merupakan penelitian tindakan kelas karena dilakukan untuk memecahkan masalah pemeblajaran di kelas. Penelitian ini merupakan penelitian deskriptif karena menjabarkan bagaimana suatu teknik pembelajaran diterapkan dan bagaimana hasil yang diinginkan dapat dicapai. Menururt Kasbolah E.S \& I Wayan Sukarnyana (2006:9) menyatakan bahwa penelitian tindakan kelas merupakan salah satu upaya guru atau praktisi dalam bentuk berbagai kegiatan yang dilakukan untuk memperbaiki keadaan yang tidak/kurang memuaskan dan atau untuk meningkatkan mutu pembelajaran di kelas.Sedangkan, Paizaluddin (2013: 7) Penelitian tindakan kelas adalah suatu kegiatan penelitian dengan mencermati sebuah kegiatan belajar yang diberikan tindakan, yang secara sengaja dimunculkan dalam sebuah kelas, yang bertujuan memecahkan masalah atau meningkatkan mutu pembelajaran di kelas tersebut. Tindakan yang secara sengaja dimunculkan.

Tempat penelitian adalah tempat yang digunakan dalam melakukan penelitian untuk memperoleh data yang diinginkan. Penelitian ini bertempat di MTsN 9 Ngawi tahun pelajaran 2017/2018. Subjek penelitian pada penelitian ini merupakan siswa kelas VIII-A MTsN 9 Ngawi. Waktu berlangsungnya penelitian ini pada awal semester dua.

\section{HASILDAN PEMBAHASAN}

\section{Siklus I}

Adapun hal-hal yang dilakukan pada 
tahap perencanaan yaitu. Penentukan materi pelajaran matematika yang akan diajarkan yaitu sudut pusat dan sudut keliling pada lingkaran dengan menggunakan metode Cooperative Learning tipe Jigsaw II.Menyusun rencana pelaksanaan pembelajaran (RPP).Membuat soal pos tes dan tes formatifMerancang pembelajaran dengan membentuk kelompok, tiap kelompok terdiri dari 5-6 orang siswa dengan kemampuan yang berbeda.

Selanjutnya adalah tahap pelaksanaan. Penilaian tidak didasarkan pada skor akhir yang diperoleh siswa, tetapi berdasarkan pada seberapa jauh skor itu melampaui rata-rata skor sebelumnya. Setiap siswa dapat memberikan kontribusi poin maksimum pada kelompoknya dalam sistem skor kelompok. Siswa memperoleh skor untuk kelompoknya didasarkan pada skor tes mereka melampaui skor dasar mereka atau disebut skor peningkatan.

Tabel 4.1. Nilai dari Hasil Pretes dan Hasil

Siklus I

\begin{tabular}{|c|c|c|c|c|}
\hline No & Nama & $\begin{array}{l}\text { Pos } \\
\text { tes }\end{array}$ & Siklus I & $\begin{array}{l}\text { Nilai } \\
\text { akhir }\end{array}$ \\
\hline 1 & $\begin{array}{l}\text { Adelia puspa } \\
\text { wardani }\end{array}$ & 40 & 60 & 50 \\
\hline 2 & $\begin{array}{l}\text { Afifah nur } \\
\text { muthiah }\end{array}$ & 40 & 80 & 60 \\
\hline 3 & Ajib tri imtihan & 50 & 77 & 63,5 \\
\hline 4 & $\begin{array}{l}\text { Alan ragil } \\
\text { saputro }\end{array}$ & 60 & 67 & 63,5 \\
\hline 5 & $\begin{array}{c}\text { Alfiani olifia } \\
\text { wati }\end{array}$ & 70 & 67 & 68,5 \\
\hline 6 & $\begin{array}{c}\text { Ardenila } \\
\text { berliana lestari }\end{array}$ & 60 & 60 & 60 \\
\hline 7 & Arfamuzi & 50 & 80 & 65 \\
\hline 8 & Della berlianti & 70 & 77 & 73,5 \\
\hline 9 & $\begin{array}{c}\text { Dewi lestari } \\
\text { mafitaningtyas }\end{array}$ & 30 & 67 & 48,5 \\
\hline 10 & Dian kurniawati & 30 & 63 & 46,5 \\
\hline 11 & $\begin{array}{c}\text { Dikan amarsa } \\
\text { aryatama }\end{array}$ & 40 & 60 & 50 \\
\hline 12 & $\begin{array}{l}\text { Diyah ayu } \\
\text { alviana }\end{array}$ & 70 & 80 & 75 \\
\hline 13 & Doris setiawan & 20 & 77 & 48,5 \\
\hline 14 & $\begin{array}{l}\text { Erval saidun } \\
\text { mustofa }\end{array}$ & 30 & 67 & 48,5 \\
\hline 15 & Fitri yuliningsih & 60 & 63 & 61,5 \\
\hline 16 & $\begin{array}{c}\text { Ibnu khoirul } \\
\text { sabililah }\end{array}$ & 40 & 60 & 50 \\
\hline 17 & Ibnu rosyid $\mathrm{m}$ & 40 & 80 & 60 \\
\hline
\end{tabular}

\begin{tabular}{|c|c|c|c|c|}
\hline 18 & $\begin{array}{c}\text { Iqbal } \\
\text { fatkhurohman }\end{array}$ & 50 & 77 & 63,5 \\
\hline 19 & $\begin{array}{l}\text { Irfan tommy } \\
\text { mahmudin }\end{array}$ & 70 & 67 & 68,5 \\
\hline 20 & Khoirul mustofa & 40 & 63 & 51,5 \\
\hline 21 & $\begin{array}{l}\text { Muhammad } \\
\text { bayu agustian }\end{array}$ & 50 & 60 & 55 \\
\hline 22 & $\begin{array}{c}\text { Muhammad } \\
\text { nabil khoirunnas }\end{array}$ & 30 & 80 & 55 \\
\hline 23 & $\begin{array}{l}\text { Najib dwi } \\
\text { imtihan }\end{array}$ & 50 & 77 & 63,5 \\
\hline 24 & $\begin{array}{c}\text { Rizky } \\
\text { hendrawan }\end{array}$ & 60 & 67 & 63,5 \\
\hline 25 & $\begin{array}{l}\text { Salma hikmatul } \\
\text { hidayah }\end{array}$ & 20 & 63 & 41,5 \\
\hline 26 & $\begin{array}{l}\text { Tria dea } \\
\text { permata }\end{array}$ & 40 & 60 & 50 \\
\hline 27 & Walid nahari & 70 & 80 & 75 \\
\hline 28 & $\begin{array}{l}\text { Wulan } \\
\text { widiastuti }\end{array}$ & 20 & 77 & 48,5 \\
\hline 29 & Yuni septikasari & 50 & 67 & 58,5 \\
\hline 30 & $\begin{array}{l}\text { Yusril hasyim } \\
\text { rosyidi }\end{array}$ & 50 & 63 & 56,5 \\
\hline 31 & $\begin{array}{l}\text { Dimas wahyu } \\
\text { nugroho }\end{array}$ & 60 & 60 & 60 \\
\hline
\end{tabular}

Dilihat dari tabel presentase peningkatan siswa diatas maka dapat digambarkan skor peolehan masing-masing kelompok sebagai berikut.

Tabel 4.2 Perolehan Skor Kelompok Siklus I

\begin{tabular}{llll}
\hline No & $\begin{array}{c}\text { Nama } \\
\text { kelompok }\end{array}$ & $\begin{array}{c}\text { Jumlah } \\
\text { skor }\end{array}$ & $\begin{array}{c}\text { Rata- } \\
\text { rata }\end{array}$ \\
\hline 1 & Kelompok A & 375 & 53.57 \\
2 & Kelompok B & 390 & 65 \\
3 & Kelompok C & 361 & 60 \\
4 & Kelompok D & 351 & 58.5 \\
5 & Kelompok E & 326 & 54.3 \\
\hline
\end{tabular}

Dari tabel diatas dapat disimpulkan bahwa jumlah siswa yang mencapai ketuntasan KKM ada 1 siswa (3.22\%). Target keberhasilan dalam penelitian ini adalah jumlah siswa yang mencapai presentasi $\geq 75 \%$. Dari hasil yang didapat dari siklus I tersebut dapat diartikan penelitian belum tercapai karena jumlah presentase peningkatan mencapai $<75 \%$.

Tahap selanjutnya adalah refleksi. Tahap ini adalah pembahasan dari temuan pada tahap pelaksanaan, dimana temuan itu antara lain siswa enggan untuk bertanya dan memilih diam dikarenakan siswa belum 
mengerti sepenuhnya dan kurang memahami materi, sehingga siswa bingung apa yang akan ditanyakan.Beberapa siswa masih pasif dan bingung dengan apa yang harus dilakukan karena siswa belum paham sepenuhnya dengan alur pembelajaran menggunakan metode cooperative learning tipe Jigsaw II. Beberapa siswa memiliki motivasi belajar yang rendah terhadap materi sudut pusat dan sudut keliling pada lingkaran, hal ini terlihat dari beberapa siswa yang kurang bersemangat dalam diskusi kelompok maupun dalam kegiatan praktik.Siswa masih terbiasa dengan belajar secara individu serta peran guru masih dominan pada siklus I ini.

Tahap berikutnya adalah tahap penyelesaian. Pada tahap ini adalah paparan pemecahan masalah yang ditemuakan pada pahap sebelumnya antara lain memberikan pengertian kepada siswa tentang pentingnya belajar kelompok terutama dalam pelaksanaan cooperative learning tipe Jigsaw II ini.Menjelaskan dan mempertegas lagi alur metode Jigsaw II kepada siswa sampai semua siswa paham sehingga kegiatan belajar berjalan lancar. Dominasi guru (kolaborator) dan peneliti agak dikurangi pada siklus berikutnya agar tercipta pembelajaran seni budaya yang terpusat pada siswa. Memotivasi siswa agar lebih berani dalam mengungkapkan gagasan dan lebih aktif lagi dalam diskusi kelompok

\section{Siklus II}

Adapun hal-hal yang dilakukan pada tahap perencanaan yaitu. Rencana tindakan yang dilakukan pada siklus II merupakan perbaikan dari siklus sebelumnya. Pada dasarnya pelaksanaan pembelajaran pada siklus II ini sama dengan siklus I. Menyusun Rencana Pelaksanaan Pembelajaran. Merancang pembentukan kelompok terdiri dari $5-6$ orang siswa secara random sehingga setiap kelompok
heterogen.Menyiapkan media pembelajaran

$$
\text { Selanjutnya adalah tahap }
$$

pelaksanaan. Penilaian tidak didasarkan pada skor akhir yang diperoleh siswa, tetapi berdasarkan pada seberapa jauh skor itu melampaui rata-rata skor sebelumnya. Setiap siswa dapat memberikan kontribusi poin maksimum pada kelompoknya dalam sistem skor kelompok. Siswa memperoleh skor untuk kelompoknya didasarkan pada skor tes mereka melampaui skor dasar mereka atau disebut skor peningkatan.

Tabel 4.3 Nilai dari Hasil Pretes dan Hasil

Siklus II

\begin{tabular}{|c|c|c|c|c|}
\hline No & Nama & Siklus I & Siklus II & $\begin{array}{l}\text { Nilai } \\
\text { akhir }\end{array}$ \\
\hline 1 & $\begin{array}{l}\text { Adelia puspa } \\
\text { wardani }\end{array}$ & 60 & 80 & 73,5 \\
\hline 2 & $\begin{array}{l}\text { Afifah nur } \\
\text { muthiah }\end{array}$ & 80 & 80 & 80 \\
\hline 3 & $\begin{array}{l}\text { Ajib tri } \\
\text { imtihan }\end{array}$ & 77 & 87 & 82 \\
\hline 4 & $\begin{array}{l}\text { Alan ragil } \\
\text { saputro }\end{array}$ & 67 & 80 & 73,5 \\
\hline 5 & $\begin{array}{l}\text { Alfiani olifia } \\
\text { wati }\end{array}$ & 67 & 100 & 83,5 \\
\hline 6 & $\begin{array}{c}\text { Ardenila } \\
\text { berliana lestari }\end{array}$ & 60 & 80 & 70 \\
\hline 7 & Arfamuzi & 80 & 87 & 83,5 \\
\hline 8 & Della berlianti & 77 & 93 & 85 \\
\hline 9 & $\begin{array}{l}\text { Dewi lestari } \\
\text { mafitaningtyas }\end{array}$ & 67 & 83 & 75 \\
\hline 10 & $\begin{array}{c}\text { Dian } \\
\text { kurniawati }\end{array}$ & 63 & 80 & 75 \\
\hline 11 & $\begin{array}{c}\text { Dikan amarsa } \\
\text { aryatama }\end{array}$ & 60 & 80 & 73,5 \\
\hline 12 & $\begin{array}{l}\text { Diyah ayu } \\
\text { alviana }\end{array}$ & 80 & 100 & 90 \\
\hline 13 & $\begin{array}{c}\text { Doris } \\
\text { setiawan }\end{array}$ & 77 & 93 & 85 \\
\hline 14 & $\begin{array}{l}\text { Erval saidun } \\
\text { mustofa }\end{array}$ & 67 & 93 & 80 \\
\hline 15 & $\begin{array}{c}\text { Fitri } \\
\text { yuliningsih }\end{array}$ & 63 & 80 & 76 \\
\hline 16 & $\begin{array}{l}\text { Ibnu khoirul } \\
\text { sabililah }\end{array}$ & 60 & 80 & 73,5 \\
\hline 17 & Ibnu rosyid m & 80 & 87 & 83,5 \\
\hline 18 & $\begin{array}{l}\text { Iqbal } \\
\text { fatkhurohman }\end{array}$ & 77 & 87 & 82 \\
\hline 19 & $\begin{array}{l}\text { Irfan tommy } \\
\text { mahmudin }\end{array}$ & 67 & 93 & 80 \\
\hline 20 & $\begin{array}{l}\text { Khoirul } \\
\text { mustofa }\end{array}$ & 63 & 97 & 80 \\
\hline 21 & $\begin{array}{c}\text { Muhammad } \\
\text { bayu agustian }\end{array}$ & 60 & 87 & 73,5 \\
\hline 22 & Muhammad & 80 & 89 & 84,5 \\
\hline
\end{tabular}




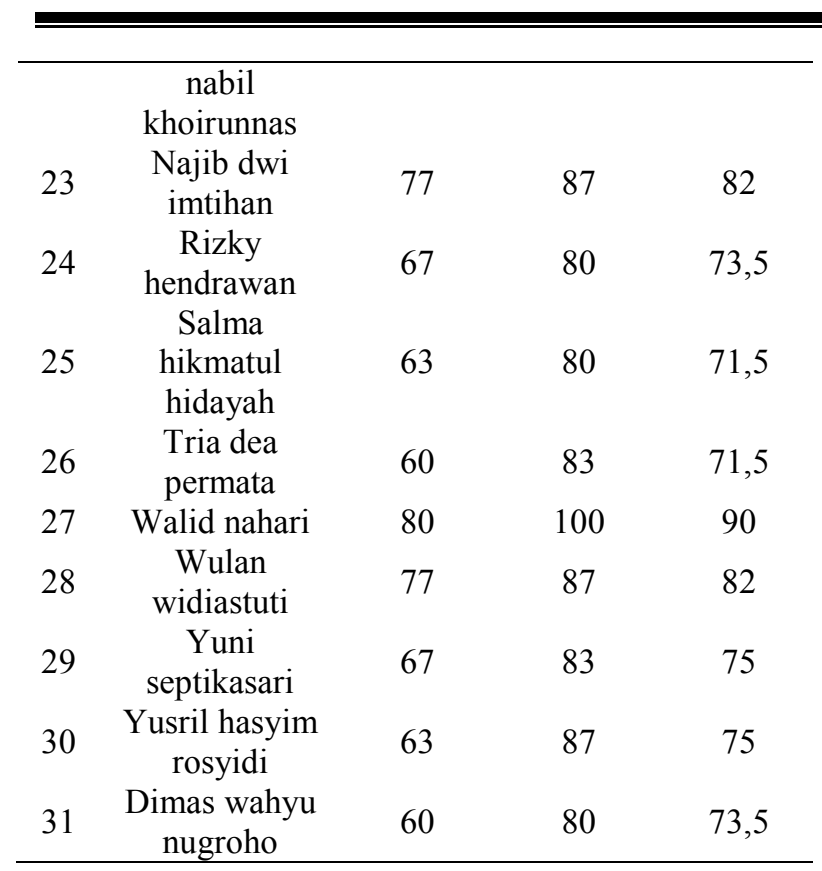

Dilihat dari tabel presentase peningkatan siswa diatas maka dapat digambarkan skor peolehan masing-masing kelompok sebagai berikut.

Tabel 4.2 Perolehan Skor Kelompok Siklus II

\begin{tabular}{cccc}
\hline No & $\begin{array}{c}\text { Nama } \\
\text { kelompok }\end{array}$ & $\begin{array}{c}\text { Jumlah } \\
\text { skor }\end{array}$ & Rata-rata \\
\hline 1 & Kelompok A & 509 & 72.71 \\
2 & Kelompok B & 511.5 & 85.25 \\
3 & Kelompok C & 498 & 83 \\
4 & Kelompok D & 457 & 76.16 \\
5 & Kelompok E & 461 & 69.33 \\
\hline
\end{tabular}

Dari tabel diatas dapat disimpulkan bahwa jumlah siswa yang mencapai ketuntasan ada 31 siswa $(100 \%)$. Target keberhasilan dalam penelitian ini adalah jumlah siswa yang mencapai $\mathrm{KKM} \geq 75 \%$. Dari hasil yang didapat dari siklus I tersebut dapat diartikan penelitian belum tercapai karena jumlah siswa mencapai KKM $<75 \%$.

Tahap berikutnya adalah tahap penyelesaian. Pada tahap ini adalah paparan pemecahan masalah yang ditemuakan pada pahap sebelumnya antara lain Peran serta siswa dalam proses pembelajaran semakin meningkat sehingga proses pembelajaran terpusat pada siswa.Siswa yang sebelumnya masih terbiasa dengan belajar secara individu dan susah membaur dengan kelompok, pada siklus II siswa sudah bisa bekerja secara berkelompok dan mengerti arti penting gotong-royong. Kerjasasama yang baik antar siswa terlihat dari kegiatan praktik maupun diskusi kelompok.

\section{SIMPULAN}

Berdasarkan hasil analisis data dan pembahasan dapat disimpulkan bahwa metode cooperative learning tipe jigsaw dapat meningkatkan hasil belajar siswa pada mata pelajaran matematika di kelas VIII A MTsN 9 Ngawi. Hal ini dapat dilihat dari perbandingan siklus I dan siklus II yaitu terjadi peningkatan. Rata-rata nilai siswa pada siklus I yaitu 69.22 kemudian pada siklus II menjadi 87.96. Rata-rata nilai kelompok pada siklus I yaitu 58.27 kemudian rata-rata nilai kelompok siklus II menjadi 93.85. Rata-rata skor akhir 1 ke siklus II meningkat 21\% Jumlah siswa yang mencapai KKM pada siklus I yaitu 3\% kemudian pada siklus II berkumlah $100 \%$. Hal tersebut sudah sesuai dengan target keberhasilan yang dicapai yaitu KKM $\geq$ $80 \%$.

Hal ini membuktikan bahwa metode cooperative learning tipe Jigsaw II dapat meningkatkan aktivitas siswa dalam belajar dan mendorong siswa untuk menjadi aktif dalam proses pembelajaran.

\section{DAFTAR PUSTAKA}

Depdiknas. (2003). Undang-Undang

Republik Indonesia Nomor 20 Tahun

2003 Tentang Sistem Pendidikan

Nasional. Undang-Undang Republik

Indonesia, (1).

https://doi.org/10.1017/CBO978110741

5324.004

Hara, B. (2009). Teacher-centered vs 
student-centered.

Permana, E. P. (2016). Penerapan Metode

Pembelajaran Kooperatif Numbered

Heads Together (NHT) Untuk

Meningkatkan Hasil Belajar dan

Berpikir Kritis Siswa Pada Mata

Pelajaran IPS SD. JURNAL

PENDIDIKAN DASAR NUSANTARA, 1(2). 49-

58https://doi:10.29407/jpdn.v1i2.210.

Uno, H. H. B. (2010). Model pembelajaran: menciptakan proses belajar mengajar yang kreatif dan efektif. Jakarta: Bumi

Aksara.

https://doi.org/10.1038/cddis.2011.1

Kasbolah E.S \& I Wayan Sukaryana. (2006)

Penelitian Tindakan Kelas

Paizaluddin, Ermalinda. 2013. Penelitian

Tindakan Kelas (Panduan

Teoritis dan Praktis). Bandung:

Alfabeta.

Permendikbud. (2003). Undang-undang

Nomor 20 Tahun 2003 tentang Sistem

Pendidikan Nasional 